Makerere College. The expansion of the Uganda Museum is another project of importance to both research and education, and will be concerned both with ethnology along lines already well established and with the evolving life of the native communities.

Every aspect of public service, such as transport and hydro-electric power, receives attention. The scarcity of coal and other fuels necessitates the utilization of the water resources, particularly Lake Victoria, Africa's greatest reservoir. A scheme involving control of the lake-level would provide an ample margin of power, over and above the demand foreseeable within the next ten years.

The maps which accompany the report are well selected, but their uniform scale is too small for the detail of the various distributions shown, and legibility is not always guaranteed.

Walter Fitzgerald

\section{THORPE'S DICTIONARY}

Thorpe's Dictionary of Applied Chemistry Fourth edition, revised and enlarged. Vol. 8 : Meths-Oils, Essential. Pp. viii +679 . (London, New York and Toronto: Longmans, Green and Co., Ltd., 1947.) 80s. net.

THERE can surely be few works of reference which provide so rich a harvest of knowledge as this latest volume, just issued, of Thorpe's "Dictionary of Applied Chemistry". Many of the writers are not only experts in their special fields of interest but are also active workers engaged in the promotion and extension of this knowledge. The impression gained by reading many of the articles written by distinguished authors is that no chemist, whether in the academic or industrial field, can venture far in his subject without having this volume for reference.

The subjects comprised under the titles from "Meths-Oils, Essential" include a mass of general topics of more than ordinary interest in present times. There are also others to which one would go for a fundamental and historical background of subjects of more common interest.

Prof. E. F. Burton of Toronto writes on the electron microscope, Dr. G. B. B. M. Sutherland on infra-red and Raman spectra, and Prof. R. A. Morton on visible and ultra-violet molecular spectra. These articles give a conspectus of present knowledge and of the methods of investigation in these fields. The editors are to be congratulated on having secured, shortly before his death, a valuable article from that veteran, Prof. V. M. Goldschmidt, on geochemistry of minerals. Minerals and X-ray analysis are ably dealt with by Dr. F. A. Bannister of the British Museum (Natural History), and Dr. L. J. Spencer contributes other articles on minerals. Dr. L. E. Sutton, of Oxford, has written on electric dipole moments. Prof. J. R. Partington has contributed the article on nitrogen and the utilization of atmospheric nitrogen, and Prof. J. H. Quastel has dealt with biological nitrogen fixation. Nucleic acids are ably discussed by the late Prof. J. M. Gulland and G. R. Barker, and there is included an article by Dr. C.J. G. Knight on growth factors for micro-organisms, a subject of current interest in view of the manufacture of biosynthetic products.

An authoritative article on octane number is contributed by Mr. F. L. Garton of the Shell Petroleum Co. and another by Dr. J. H. Burgoyne on methane as fuel. Micro-chemistry in most of its aspects dealt with in great detail, including micro-chemical operations and drop reactions and organic micro. analysis. The major contribution to this volume is that by Dr. E. H. Rodd and his collaborators on naphthalene, which covers this field and provides an important monograph in itself and occupies 176 pages.

Generally the standard of the articles is high and the space allotted to each subject adequate, in some cases amply so for a chemical dictionary. Care has been exercised in the selection of contributors, and in many cases these are men of front rank. Where a large field must be covered in limited space, as in the article on high-vacuum distillation (molecular distillation) by Dr. K. C. D. Hickman of Rochester, N.Y., an exhaustive bibliography accompanies the article. A noteworthy contribution is one on molecular beams by Prof. O. R. Frisch of Cambridge.

The volume is well presented on good paper with ufficient margins and a sturdy binding.

NORMAN HAWORTH

\section{QUALITATIVE QUANTA}

\section{The Stringe Story of the Quantum}

An Account for the General Reader of the Growth of the Ideas underlying our Present Atomic Knowledge. By Banesh Hoffmann. Pp. xi+239. (New York and London: Harper and Brothers, 1947.) 3 dollars.

T $T$ is perhaps ungrateful to begin the review of this. delightful look with a complaint, but it is surely unnecessary to state Planck's constant on p. 22 as a pure number. Apart from this, the reviewer must add that no book of popular science since 'Mr. Tompkins' ' exploration of the atom has given him such keen pleasure in the reading.

The object of the book is to give for the benefit of the general reader as complete an account of the development of moden quantum theory as is possible without the use of mathematical symbolism. Dr. Hoffmann's general reader, however, must be gifted with an uncomnon degree of intelligence and mental agility if he is to derive any clear idea of the developments after 1925 of the theory from a first reading of this book. The author's method of presentation reminds one of a man with a club hewing his way through a lostile mob. The historical development is followed quite accurately, and us each point arises, the probable consequent misconceptions are mustered presented in their most formidably persuasive form, and then, in the next paragraph, down comesthe club. They are knocked on the head and dropped in the gutter, and Dr. Hoffmann advances trimphantly, with the reader, a little breathless and apprehensive, tugged along in his wake. This is shovmanship in the grand style, but there is no sacrifice of accuracy in the physics for its sake.

"The Strange Story of the Quantum" succeods above all in showing that science is no static dry-asdust body of knowledge. The author's quick-moving style recreates the excitement of the mid-1920's when quantum theory was beginning to assume its modern form. He makes it clear how successive ideas came into contradiction with experience and were replaced, and he emphasizes the pecarious state of the present day physics, with relativity and quantum theory uneasy bedfellows. The pages carry a foam of witty 